\title{
The organisational politics of meetings and their technology - two case studies of video supported communication
}

\author{
John Hughes, Steinar Kristoffersen, Jon O'Brien, and Mark \\ Rouncefield \\ CSCW Research Centre, Lancaster University, U. K, \\ phone: +44 1524594 186; fax: +44 1524594 256; email: \\ steinar@comp.lancs.ac.uk
}

\begin{abstract}
This paper reflects on the introduction of video based communication systems, using empirical studies of two large commercial organisations: a national high street bank and a technical research centre in a multinational manufacturing company. The study suggests that although corporate philosophy and politics can create a drive towards exploring a set of technologies, they can simultaneously encourage a way of organising and managing work that conflicts with that particular implementation. The need to resolve conflicting political and social contingencies throughout the implementation, introduction and evaluation of new technology must be recognised. Precise requirements and design implications are hard to formulate, and our proposal has important implications in that it points beyond the traditional requirements engineering and work study approaches to systems design and introduction.
\end{abstract}

Keywords

Introduction, adoption, video conferences, computer supported cooperative work, requirements engineering, work studies, politics and principles

\section{INTRODUCTION}

As multimedia technology becomes less expensive and easier to use, video communication will become a salient feature of many applications for Computer Supported Cooperative Work (CSCW). Video can support non-verbal communication and peripheral awareness (Pagani \& Mackay 1993), informal communication (Root 1988), and contributes to the rapport within groups of geographically-dispersed individuals (Abel 1990). Users like video (Tang \& Isaacs 1993), although work exists to suggest that the value added by real-time, visual communication is negligible (cited in Tang \& Isaacs 1993), and that the success of teleconferencing has fallen short of commercial expectations (Egido 1988). However, few such systems have moved beyond the laboratory and, consequently, there have been few opportunities to consider and evaluate the use of cooperative multimedia within natural work settings.

While research continues to suggest the potential of CSCW solutions to the 
coordination of distributed working (Malone et al. 1987), it is still the case that organisational implementation is frequently less than straightforward, involving not merely technological issues but also important organisational factors (Orlikowski 1992). Similar experiences have been made throughout the history of IS development (Keen 1981; Kling \& Iacono 84). Controlled experiments in laboratory-like environments often show increased technological efficiency and effectiveness, however, and in contrast, the move into the 'real world' of organisational use often proves disappointing (Dennis et al. 1990; Grudin 1994; Greenberg 1991; Egido 1988).

While there are technological challenges in developing effective video systems, this paper emphasises the importance of looking at the technology as enmeshed in the 'politics' of organisational life and asserts that this needs to be taken into account when assessing the implications of video technology.

The two case studies considered here allow us to offer some evaluation of video communication systems in use, albeit systems which are used for different purposes: selling a product, as in the bank, and holding a meeting, as in the technology centre. Whilst small in scale, these two examples are intended to illuminate the wider context which bears upon the effectiveness of video based systems.

The first empirical study on which this paper is based concerns the introduction of a video based communication system in a large UK bank. Radical reorganisation had centralised some of the more specialised functions of the bank's services so that high street branches had to deal mainly with counter customers, calling on the centres for more specialised services. The role of the Telehelp team in the bank's national insurance centre, is to give customers advice about home insurance and related matters. A commercial, ISDN-based, desktop video conference system, with task-dedicated workflow software developed in-house, has been implemented to support the communication with customers and staff in selected branches. The video link was installed in the Telehelp team for a 6 month trial period, staffed by specially trained personnel. The study is based on 12 days' ethnographic observation, taking place over a period of several months in 1994/95.

The second study is from an investigation of a laboratory in a technology centre, belonging to a multinational company. The technology centre employs a dedicated facility video conference system to facilitate meetings with stakeholders throughout the company. Observations lasted approximately four weeks over a period of two to three months in 1994.

\section{RESEARCH METHOD}

The research method adopted in these studies is broadly that of ethnography. The distinguishing characteristic of this approach is the researcher's involvement in the milieu of study, and whose role is to provide 'thick descriptions' (Geertz 1983) of the circumstances, practices, conversations and activity that comprise the 'real world' character of everyday work settings. The general advantage claimed for ethnographic approaches in design lies in the 'sensitising' it promotes to the real world character and context of work. Such research begins by seeing the social world from the point of view of the participants, and by examining the ways in which the work activities actually get done. This emphasis provides an important analytic tool for the examination of work as lived experience, and important clues as to both the 'how' and 'why' of everyday working practices. Although the use of technology is but one aspect of these studies, in the design context ethnographic approaches focus on the various ways in which technologies, including video systems, are enmeshed in the everyday flow of work as experienced by those in the setting. 
Traditionally, problems associated with the introduction of systems have predominantly been defined from a development perspective (Andersen et al. 1986) in which insufficient analysis, careless design or incomplete testing and narrow communication lines on the managerial level are seen as paramount problems. Previous work also takes the stance that lack of success stems from an organisation reluctant to change, even for the 'obvious' benefit of the enterprise. Thus, the job of the system designer includes the necessary effort to persuade managers and workers into changing the organisation of work, the work procedures, or even the people and their skills, to accommodate the technology being introduced.

To facilitate the adoption of multimedia technologies to support cooperation, Francik et al. (1991) suggest that several issues should be carefully considered: i) Identifying the suitable application domain in which to introduce the system; ii) Assisting the members of the organisation to envisage future use; iii) Selecting the right group for a pilot test situation; iv) Being careful not to ignore the actual distribution of work; v) Assessing existing support for communication; vi) Assigning equipment to group members according to the nature of the work they perform rather than the traditional roles of manual office routines; and vii) Acknowledge the importance of training.

As the following empirical studies suggest, adhering to such principles is no guarantee of success: in the example from the bank a thorough 'adoption exercise' like the one outlined above was carried out and yet the system has failed to meet expectations. 'Video links', like many other technologies past, present and, no doubt, future, are introduced and developed in accord with a range of organisational, managerial and local priorities and policies; priorities and policies that are themselves subject to change and may even, in some instances, be in conflict (see, for example, Yates 1989).

In the bank, the desktop video conference system became the central component of the RATE (Remote Access To Expertise) project. Internally known only as the Video Link, it had been installed in the 'Telehelp' section of the Insurance division. One aim of this 6 month part of the project was to obtain customer and staff feedback. The bank's research department also wanted to consider other possible applications, such as in Home loans and in the Foreign and Commercial sectors, as well as assessing potentiality for a much wider use in fostering the collaboration between staff in service centres and branches. Similar considerations motivated the introduction of video conferencing in the technology centre and was a central element in the IT strategy proposing to use electronic means to support the use of expertise between remote sites of the company.

In what follows we present fieldwork materials to illustrate the video technology in use in both the bank and the technology centre. Our aim is to show how larger organisational issues can interact, in complex ways, with the use of the technology under consideration.

\section{INSTANTANEOUS ACCESS TO EXPERTISE}

\subsection{Strategic Context}

The role of the Telehelp team is, in line with the strategy of the bank to centralise specialised services in order to reduce costs, to give insurance advice to customers from branch offices. The following are integral to this strategy. Firstly, increased routinisation of cases brings the cost down. Not only are exceptional cases more timeconsuming to evaluate and record, but the decision making process itself requires costly expertise. By offering a standardised product, the bank can rely on less educated, 
younger staff. This is traditional hierarchic organisational design and, as long as the exceptions are easily dealt with, eg. by referring 'difficult' customers to other companies, it works well and the risk profile is maintained. Secondly, centralisation of expertise is one of the bank's explicit organisational goals. Service centre staff used to work in the 'back offices' of the branches. By bringing these 'back office' staff together, many more branches can be served as well as reducing managerial and training costs. Finally, increasingly international and competitive markets, alongside a more mobile customer base, have forced the bank to abandon its traditional 'administrative' focus. Not only has the business expanded and taken up new areas, such as insurance, but reduced profit margins have made the product focus paramount. Banking is now the in the business of 'selling' a wide range of financial products.

The 'macro' organisational context for the introduction and use of the Video Link was, therefore, a complex scenario of implementing and evaluating a new technology whilst responding to changing market, managerial and organisational pressures. Like other financial institutions, the bank was involved in improving profit margins by cost reduction through the centralisation of 'back office' processing and 'deskilling'; both requiring heavy investment in IT. At the same time the bank was attempting to defend its 'market share' by endeavouring to change from an organisation that had traditionally been concerned with administration to one that focused on selling.

\subsection{The use of the Video Link and Workflow system}

One integral part of the Video Link system was the Workflow package designed to be used alongside it. From the managers' perspective, workflow systems are valuable because they enforce the business rules. In this case it was intended to ensure that all the accepted home insurance covers issued complied with the risk profile of the unit. Equally important was the normative effect on the behaviour of the workforce, making control easier and reducing the need for training. With a well-designed workflow system, people with little or no background in banking or insurance could be brought in to sell policies, because all the rules would, ideally, be maintained by the system. On the other hand, the workflow system was also expected to make better sales' people out of 'back office staff' by displaying on the screen the right responses to negative customer reactions, alongside a suite of effective selling expressions. There was a general belief that the customer needed to feel that they were speaking to an 'expert' capable of providing a service above that offered by the branch staff, thereby building confidence in bank services which, it was hoped, would then be extended to the purchase of other bank products and services.

The first releases of the Video Link package included document sharing and a whiteboard, but was later reduced to a simple Video Link and screen transfer of completed documents. ${ }^{1}$ At the time of the study customers were only shown the finished form and asked to confirm details.

This fieldnote extract displays a 'typical' session:

1.... using video link - intro - host at branch; customer...using headset (problem of feedback when using speakers) - customer using speakers.

2. Using screen - filling in details on form - asking customer questions - name; date of birth; initials; occupation; post code - then tells customer address - street/rd - (say that this impresses customers) asks for house number

3. Transfers info over - explains that this will take a few seconds and will make her image break up/go fuzzy a bit - asks to check if its $O K$.

4. Goes through policy - filling in form on screen - and asking customer questions - building and contents; rebuilding costs; contents; accidental damage; away from home.

5. Transfers quote over - explains again about the image breaking up.

Initially customers had 'shared' the documents as they were being prepared by staff, but spelling mistakes had tended to erode customer confidence. The managers also felt that if they made the customer focus on the document-oriented nature of work, they would miss out on the most important part the interaction from the bank's perspective. namely the non-verbal communication and facial expressions of the specialist, thus making up the 'sales pitch' 
6. Goes through the figures - gives details on policy - what it covers in addition - cycles; frozen food; $£$ 2 million owners liability; - and outlines repayment details .

7. "Do you know roughly what you are paying at the moment?"

8. Offers to print out quote - to take away and compare.

9. Takes daytime telephone number - "in case we need to contact you for any reason"

10. Gives 'official data protection script - on card in front of screen.

11. Transfers 'features and benefits' of policy (a list of other items covered by the policy).

12. Customer does questionnaire in branch - operator has headset on - can hear

13. Gets printout.

\subsection{The nature of work and management}

At the time of the study the Video Link was set up between the Insurance Centre and ten branches. Staff, selected for their insurance expertise, had been trained to use the Video Link. The training had to a large extent been presentation-oriented, and the specialists had also received instructions about how to use the workflow system. The branches would 'prepare' the customer for the Video Link emphasising the expert status of the person at the other end. ${ }^{1}$

The Telehelp team was managed in a process-oriented way with a light panel keeping them continuously updated on average service, waiting time, calls answered and calls in the queue. The panel also showed how many of the group's members were 'not ready' and performance sheets for each period were displayed. Company policies were implemented both as a set of managerial sanctions as well as socially through various forms of peer pressure. The emphasis on 'sales points', a metric assessment of the commercial value of each transaction, can, not surprisingly, create conflicts. It is in this context of intense pressure to perform that the Video Link would eventually be evaluated.

\subsection{The work that makes technology work}

The fieldwork reveals the considerable amount of 'work to make the Video Link work' both in the immediate context for the operator and, in the context of 'microorganisational politics', for the Manager of the Telehelp team. For the operator this consists of demeanour and 'face' work to make the customer feel at ease, as well as the articulation of Video Link work with other aspects of the organisation of insurance cover; work that takes place away from the 'video booth'.

Throughout the 'Video Link process' the operator is engaged in extensive and skilful 'demeanour work' consisting of exaggerated smiling, nodding and facial gestures as well as varied conversational asides and 'jokes', maintaining a sensitivity to the customer's reception of both the technology and the information on insurance. This is accomplished whilst the operator is simultaneously completing the insurance details; a not inconsiderable task since in order to 'look' at the customer the operator has to orient herself to the camera on top of the screen and cannot actually see much of the screen containing the customer's image and the document - in front of her. There is also a considerable amount of 'talking through the technology' - explaining to the customer what is happening, or is about to happen on the screen; explaining, for example, that "the image will go fuzzy for a moment because of the amount of information I am transferring" and so on, giving an 'account' of the ongoing transaction in a manner that will be easily understood and accepted. This 'account' includes conveying an impression of the bank's policies as 'quality' policies, (and therefore not the cheapest). That this is not a simple or straightforward process is illustrated in the next fieldwork

\footnotetext{
1 The interesting point to observe is that the Insurance Centre's specialists are not really supposed to be insurance experts; they are, on the contrary, trained to follow procedures and either ask their supervisor to sanction exceptional or difficult cases, or plainly reject them. Their expertise lies in being able to use the system effectively.
} 
extract when the operator suddenly finds herself dealing with an 'awkward customer' in this instance the operator effectively 'freezes' her 'body language' but begins to engage in extensive explanation and justification of the details of the policies, thereby displaying her 'expertise'.

1. Phone - 'live' call

2. Puts on headset - brings up screen of branch and assistant.

3. "Hello ...(looking at camera)..turn the screen slightly"

"My name is...I need to take some information (gives standard script on information)..is that $O K$ ?"

(Some problem here - later emerges that the customer said "No" and "if you send me details of any insurance I'm going to contact my PFA (Personal Financial Adviser) (At this stage the operator 'freezes' and becomes very formal and exact in what she says)

"Obviously that's why we ask at the beginning"

4. Explaining about transferring information and picture freezing

5. Asking for details and filling in screen - surname; initials; date of birth; occupation (mature student "what subject are you studying"); postcode - gives street; number of house.

6. Explains what the insurance is - not connected to Life Insurance Department.

7. Transfers information over - "Can you just check that that's correct?" - explains about postcode and address - stores it at this end.

8. Going through details - rebuilding costs; buildings and contents; accidental damage; items taken away over $£ 1000$; total taken away from home at any one time - "we have a minimum sum of $£ 2500$ - I'll quote you for that" "I'll transfer that - its just a premium indication and may be subject to future..(Interruption - asked question - answers "not at the moment")

9. Paying the policy - "I can print off the quotation - put some details on the screen in front of you some of the benefits..

10. Going through screens - printing options.

11. Asked question - answers "what do you mean? - if you have an alarm - if its an alarm with a service contract you can have a 5-10\% discount..Is it approved by NACODS? - then you can have a 10\% discount. There is an endorsement you must sign - that the alarm must be switched on - then there is a theft excess of $£ 250$ - some people don't like it.."

12. "I'm going to amend your quote to have the discount for having an alarm"

13. Customer asks question about letting out another property - "Is it let to professionals?"

14. Gets details of properties.

15. Customer asking questions - operator explains about going back to amend policy.

16. Asked question - "There is another one I can use." - using screen - cover choice - for house that is let.

17. Transferring data.

18. General chat about video link - "You wouldn't want to see me full size"

19. "Printing off quote for you now"

20. Answering questions - "H.(branch assistant). will give you one of our information packs.."

21. "Good-bye" - call ends.

22. "What a prat" Explains what the customer (a Physics postgraduate) was saying about the kit - that the mike was too big; the picture too small; he didn't like the delay; felt it was outdated. "I didn't like him..I let my feelings get the better of me.."

For the Manager there is a need to balance his resources between the telephone and video lines; to ensure staff support for the Video Link and to attempt to encourage branch utilisation of the link. The comparative infrequency of calls had reduced the manning level of the video booths so that at the time of the study branches were phoning the Telehelp section in order to get the booths ready and manned for incoming calls. Again this was a product of the 'micro-organisational' politics of the office. The selection and training of an 'elite task force' for the Video Link was a process which, in its identification of expertise had, apparently, created some tension within the section. The Telehelp team worked under intense pressure to answer calls and besides the manager's concern to keep the 'response rate' high (at an average of 6 seconds wait). There was some resentment that the RATE team were not 'pulling their weight', the Video Link sessions taking considerably longer to complete than the telephone interviews. 


\section{6 'GLOBAL’ DIFFUSION OF EXPERTISE}

Fieldwork at the technology centre occurred at a time when the organisation of the company to which it belonged was undergoing major restructuring, indeed these changes were frequently mentioned as taking place 'more or less all the time at the moment'.

Essentially what was taking place was a move away from a hierarchical 'divisional' and 'national' organisation towards what company members referred to as a 'global footing'. This new organisational configuration bought with it new requirements for the work of those in the technology centre. Competition between sites within the company was fostered and, as a result, technology centre staff were no seen as serving only the production sites within their UK division. Instead, they were to serve the "entire company', taking part in the internal competitive process and seeking funding for new research and development in partnership with sites from various units in the 'global organisation'.

This new organisational configuration was explicitly underpinned by an IT strategy fostered by senior management; in particular the use of electronic communication technologies was encouraged as a means of supporting the kinds of contact required between staff at widely distributed sites within the company. In particular, video conferencing was introduced as a means of holding meetings with other sites, in an attempt to maintain the 'richness' of interaction typical of face-to-face meetings.

A number of these video conferences were observed between members of technology centre staff and members of the company based at other sites. These latter are the 'customers' of the centre's work, and are considered very much in these terms, rather than as members of the same company, and the need to maintain appropriate formal relationships, as with any 'external' customer, is a strong one. The importance of such meetings has increased considerably since the organisation's reconfiguration took place. Since Centre staff no longer directly serve other sites within their 'division' of the company, they must establish collaborative relationships with others on an ad hoc basis, as contracts are gained and lost throughout the wider company. As a result, on many occasions, such meetings are increasingly to do with establishing the precise nature of an offer of collaboration, negotiating and confirming funding details and a whole range of similar tasks. As a result of the more 'competitive' basis of the organisation's configuration, ('basically a kind of internal market' said one member of staff) these meetings were characterised by participants from the Centre as 'less to do with working with people you know and trust', and more to do with establishing and maintaining important new working relationships for the Centre.

There were two Centre staff taking part in each conference that was observed. Meetings were arranged over the phone in advance, with parties to the meeting specifying suitable, mutually convenient times for the conference. The majority of our discussion here will be based upon some detailed observations of one of these video conferences':

\subsection{Working Through the Technology}

At the outset of each conference, time was spent ensuring that the software was functioning appropriately and that the image at each site was of a sufficient standard. This process typically took a few minutes, and was also treated as 'warm up' time, with 'jokey' interaction taking place between participants at both sites, before the business in hand was tackled in the meeting proper. The video camera placed on top of the PC monitor had, on most occasions, to be tilted downwards by wedging a book underneath its base in order that it could pick up those sitting on the low chairs found in that room.

The meeting discussed here is not one in which Centre staff are dealing with unknown parties, but it is nevertheless of importance. It is illustrative of many of the

\footnotetext{
1 While this is not necessarily representative of the possible range of video conference meetings
} it does provide insights into the types of interactions and practices that develop around such technology. 
issues arising out of the exploration of this type of technology. This meeting had been called to discuss a document that had been produced and circulated by members of the Quality Management team at the technology centre which dealt with the reporting procedures connected to joint projects between the Centre and the Production Site. The particular concern is with consistency across a group of documents. As is clear from the following transcription extract from the meeting, the point at which the assembled conferees are called to order to begin the meeting proper is one which is not entirely clear to all:

$A$ (a member of Technology Centre staff), $B \& C$ in the production site, $D \& E$ in the Technology Centre

A: You really need an inset of your own image don't you? [He appears to be switching between the technology centre's camera and his own - this is not clear to the Centre]

D: Eh?

A: I wasn't talking to you!

C: Hahaha

[All laugh]

B: I can't see you D ... sit up

E: Simultaneous \{Shall we start?

$D$ :

‘Am I OK now?

[Pause]

A: Yeah, $O K, O K$ do we want to start?

D: Can you see me?

[Pause]

E: Can you see him?

$B \& A$ : Yep, yep no problem

[Pause]

A: Let's start ...

E: OK ... have you all got the agenda? it's only going to be brief?

C: Yes (holds it up to camera)

As the business of the meeting continues it becomes clear the difficulties the participants are experiencing with the video conference: there is a very clear echo of each individual's words a second or two after they speak, which impacts on the ways in which the participants talk to each other: there are abnormally long pauses between sentences, as participants seem to leave sufficient time for the echo to die down, and to be sure that the conversational cues being offered are ones that imply turn-taking to be appropriate. Furthermore, throughout the meeting all individuals enunciated their words extremely clearly, adding to the 'stilted' or 'unnatural' feel of the conversation. The slow frame refresh rate meant that the images of the other participants on the screen appeared jerky and somewhat blurred, this seemed to make following visual cues particularly difficult to follow. The following transcript illustrates these kinds of issues:

A: [Finishes sentence]

[Echo]

[Pause]

E: [Leans forward] [Speaks loudly and slowly]Can I say something?[Echo - appears to wait for echo to fade, checks those at Production Site on screen, all three nod vigorously] [Starts to speak]

C: [Simultaneously] Go ahead

[Pause]

C: Sorry go ahead

$E: O K$

What is clear here is the amount of 'work' that has to be done by conference participants to maintain some form of conversational 'flow': the exaggerated nature of turn-taking cues, and the highly demonstrative use of body movements are all made use of to compensate for the crude image and sound quality provided by the video link.

As the meeting progresses they discuss sections of the document to hand and all participants appear to focus more particularly upon the discussion document rather than upon the screen with the other participants upon it. Wrapping up the meeting is also bounded by a certain degree of overt demonstration on behalf of the participants.

E: Is there anything else we should discuss?

[Pause]

D: Did you get the package? 


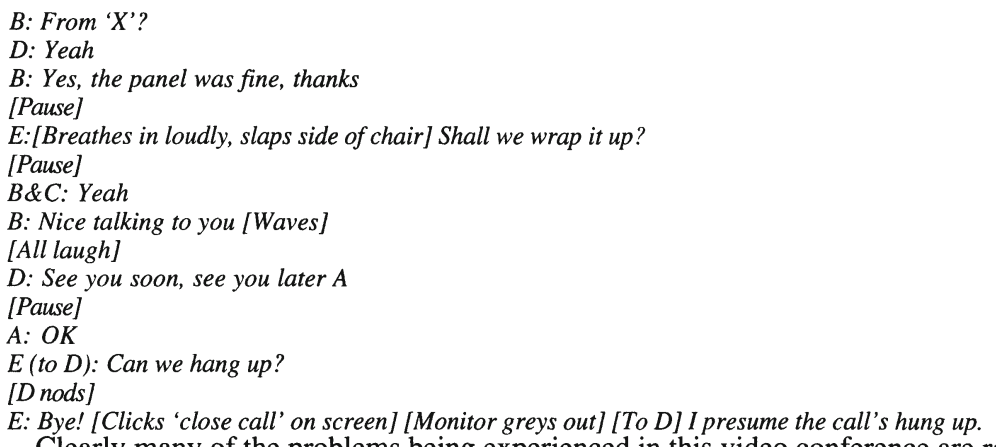

Clearly many of the problems being experienced in this video conference are related to the developing state of the technology. The staff are well aware of the limitations of this technology, and swap stories of their experiences with it. After the conference discussed above, D tells $\mathrm{E}$ of the time that he had faxed a document for discussion through to the external site, started the meeting, confirming that the fax had arrived which was confirmed by holding it up to the camera - and entered into a discussion of the document in hand. It was five minutes before they realised that there had been a mix-up of faxes and they were discussing different documents. There was a clear need for a facility, argued D, for 'proper' desktop conferencing, where electronic versions of documents might be discussed and updated effectively. The appropriate software had been ordered, stated E, and it was just the need for the $64 \mathrm{k}$ bandwidth that was holding things up. He added:

"You can't really see what they're doing, but you know that they're doing something and you can't really say "What are you doing?" It makes it difficult to keep up a steady flow of conversation."

As the technology currently stands then, there is little or no scope for the 'added value' of a visual dimension to the conferencing set up, as was made clear by A on his return to the technology centre:

"I'm saying nothing! I don't like it .. I don't like it at all. Until the technology improves you

can't really achieve anything that you can't do on the telephone.

The description of the organisational context within which the video conference facility has been introduced, makes clear the expectations possessed by the policymakers within the company with regard to this technology. However, as the fieldwork shows, the introduction of the technology has not kept pace with these policy decisions and, accordingly, fails to come up to expectations.

The crucial nature of such meetings for the Centre's personnel meant that, for many staff, such experiences with the technology were discouraging. On one occasion, serious problems were emerging with an overseas subsidiary of the company, and a meeting at directorial level was required. The Centre's head accountant explicitly ruled out the notion of holding a video conference with these individuals, since they would need to "Stare the buggers in the eyes and see which way they twitched". There was a real sense that the video-based technologies could not support such boardroom subtleties, and as such were not appropriate for the kinds of tasks they were intended to support. Thus, the perhaps hasty introduction of these technologies over a slow link has led to somewhat negative impressions of the role of the technology within the crucial working practises of the Centre staff, and subsequent scepticism regarding the policy behind such introduction:

"Little boys with new toys ... they don't play with soldiers anymore, they play with technology"

The implications of this scepticism reach beyond a straightforward 'dislike' of the technology, and highlight a range of important issues associated with the introduction of new technologies within an organisation.

In this example from the technology centre a new organisational configuration has been supported by the introduction and exploration of the potential of video 
technologies for holding meetings. At the same time this reconfiguration has generated new requirements of the work of staff at the Centre concerning, in particular, the nature of the meetings in which they participate. Whereas previously a more stable set of established collaborative relationships underpinned the majority of meetings with other sites within the company, the Centre now operates within a competitive 'internal market' and staff increasingly find that meetings are the occasions at which delicate negotiations are carried out with those who cannot necessarily be 'trusted'.

Thus the role of meetings within the organisation has shifted as well as the means by which they take place: the organisational reconfiguration has implications both for the technology being explored as part of this reconfiguration (the introduction of video conferencing) and the working practices this technology is intended to support. Increasingly, the need to 'stare the buggers in the eyes', for example, and other such boardroom manoeuvres is emerging in these meetings as a result of the more competitive basis of the company's organisation. What has emerged here, then, is the fact that the technology under exploration cannot support the new practices related to the same sets of organisational concerns.

\section{DISCUSSION}

In this paper we have looked at two attempts to introduce video-based communication technology into commercial organisations, both of which have not been entirely successful, although the technology is still under evaluation. A number of complex and contradictory organisational pressures are involved here. For example, the bank's emphasis on 'customer service', on being "first choice for customers" might be regarded as fundamentally conflicting with the heavy emphasis on centralisation, standardisation and routinisation of procedures. These same pressures can be seen in the introduction and evaluation of the Video Link - the customer service it provided, of individual, personal 'remote access to expertise' had to be balanced and judged against commercial considerations of time and sales produced. The advice and sales arguments can be better formulated if the advisor recognises the type of person on the other end, managers claimed. This is presumably easier across the video link compared to the phone. This means that they expect the specialist to be able to detect and interpret, but also respond in a meaningful way to concerns like: "What turns the customer on?", "Does the customer ask many questions?", and "Is he concerned?". This is strongly in contrast with the fact that the current trend is towards integration of all support with workflow systems, an efficient way of enforcing the plan and standardising the process, as illustrated in figure 1.

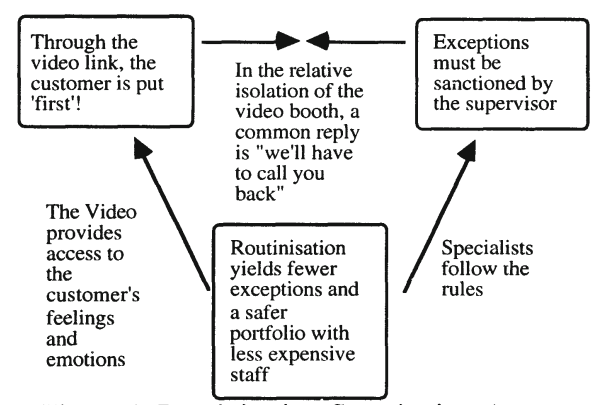

Figure 1. Routinisation-Sanctioning-Access

In the bank, a complex picture emerges since the Video Link provided the requisite remote access to expertise, albeit the 'normal' commercial pressures of time and sales completion and 'value added' suggested the inadequacy of the link in this particular 
context. Part of the explanation of why this particular introduction failed, is the tension between strategic expectations and local implementations for fulfilling these expectations. For example, the video based interviews are longer, they are hosted by two people instead of one, and they put the specialist as well as the customer in a situation in which "it is difficult to say no". Clearly, while the bank was hoping to benefit and learn from its experiment with the Video Link, it also held certain expectations of the technology focusing on its extension into other areas of bank services and the possibilities it offered of improved profit, market share and 'addedvalue'. While there was a recognition within the bank of a need to 'embrace the future' and experiment with different forms of multi-media and communication technology, there was also a contrasting, and day-to-day, pressure on 'generating results yesterday' and clearly demonstrating profitability. One aspect of the local culture is the importance of achieving sales points and meeting the bank's expectations. One consequence is that whilst the branches would be keen not to 'hand over' a VIP customer to the Centre, they would try not to spend resources, eg. host a video conference, on people that they did not expect would 'buy the product'. It was into this complex organisational 'culture' therefore, that the Video Link was introduced and evaluated, as illustrated in figure 2.

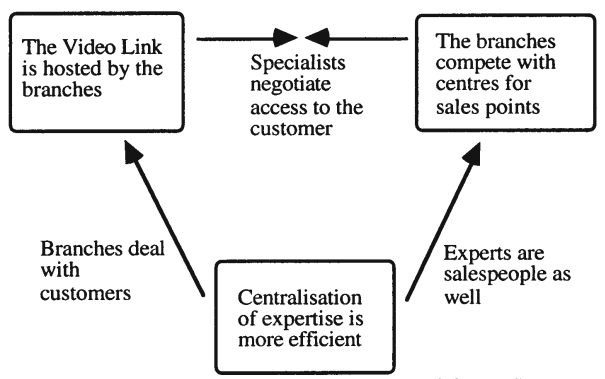

Figure 2. Centralisation-Competition-Host

In the technology centre, changes in the organisational context within which its staff have to operate to one which is more 'global' in nature, working in partnership with those not necessarily co-located, as they were previously, within the division of the organisation, has brought about changes in the nature of the meetings which are needed. One element of the company's policy has been to use video-based communication in order to facilitate meetings between distant sites; in the example discussed here, however, the policy-makers' expectations of the technology have not been fulfilled, since the slow link has prevented personnel holding meetings in a manner appropriate for the organisational importance of such meetings. As a result, both the technology and policy have become seen as inappropriate for dealing with the broader organisational changes with which they are designed to cope.

The studies reported here support the argument that the implementation of new technologies needs to attend to the complex interactions between corporate philosophy and, particularly, how this, in the local settings of the organisation of the work, can affect the introduction and adoption of new technology. In both these cases, the introduction of video-conferencing technology was ill-suited to the organisational politics engendered by wider organisational changes. The technology was offered as a way of 'fixing' organisational problems but, in the event, created further problems for those who had to use the technology and, through this, induced no little scepticism not only about the technology but also about the general strategy of reorganisation. 
Support for this work was provided by the UK's Engineering and Physical Sciences Research Council under the DTI/EPSRC programme on CSCW, the Research Council of Norway as part of project 100268/410 and Norsk Regnesentral. We are grateful for the constructive criticism given to us by the anonymous reviewers and to all those who kindly allowed us to observe their work.

\section{REFERENCES}

Abel, M. (1990). Experiences in an exploratory distributed organization. In Galegher, J. et al. (eds). Intellectual Teamwork: Social Foundations of Cooperative Work, Lawrence Erlbaum Associates. Hillsdale, New Jersey.

Andersen et al. (1986). Professional Systems Development: Development, Experience, Ideas and Action (in Danish). Teknisk Forlag. Copenhagen.

Dennis Alan R., Jay F. Nunamaker, and Douglas R. Vogel. (1990) A comparison of laboratory and field research in the study of electronic meeting systems. Journal of Management Information Systems, 7(3).

Egido, C. (1988). Videoconferencing as a Technology to Support Group Work: A Review of its Failure. In Proceedings of ACM CSCW'88 Conference on Computer-Supported Cooperative Work.

Francik et al. (1991). Putting Innovation to Work: Adoption Strategies For MultiMedia Communication Systems. In Communications of the ACM, 34(12).

Geertz, C. (1983) Local Knowledge. Fontana. London.

Grudin, J. (1994). Groupware and social dynamics: Eight challenges for developers. InCommunications of the ACM, 37(1).

Greenberg (1991). Personalizable groupware: Accommodating individual roles and group differences. In Proc. European Conference of Computer Supported Cooperative Work, Amsterdam, September 1991.

Keen (1981). Information systems and organizational change. InCommunications of the ACM, 24(1).

Kling, R. and Iacono (1984). The control of information systems development after implementation. In Communications of the ACM, 27(12).

Malone, Thomas W., Kenneth R. Grant, Kum-Yew Lai, Ramana Rao, and David Rosenblitt. (1987). Semistructured messages are surprisingly useful for computersupported coordination. ACM Transactions on Office Information Systems, 5(2).

Orlikowski (1992). Learning from notes: Organizational Issues in Groupware Implementation, In Proceedings of ACM CSCW'92 Conference on ComputerSupported Cooperative Work.

Pagani, D. S. \& Mackay, W. Bringing Media Spaces into the Real World. (1993). In Proceedings of the Third European Conference on Computer-Supported Cooperative Work.

Root, R. W. (1988)., Design of a Multi-Media Vehicle for Social Browsing. In Proceedings of the ACM CSCW'88 Conference on Computer-Supported Cooperative Work.

Tang, J. C. \& Isaacs, E. (1993). Why Do Users Like Video? Studies of Multimediasupported Collaboration. In Computer Supported Cooperative Work (CSCW), 1 (3).

Yates, J (1989). Control Through Communication: the Rise of System In American Management, Baltimore, The John Hopkins University Press. 
Professor John A. Hughes, b. 20.3.41 in Sheffield. BA (Birmingham) Class I, Ph.D. (Lancaster) 1982. Taught at the Universities of Birmingham, Exeter, Lund : teaching and researching at Lancaster since 1970. Visiting Scientist at Interval Research Corporation, Palo Alto. Since 1986 has been the recipient of Research Council grants on air traffic control, and technological change in the police, Tri-Council support for collaborative research with computer scientists on air traffic control and software development, Deputy Director of ESPRIT Basic Research Project, COMIC, and DTI/EPSRC projects Sycomt and VirtuOsi.

Steinar Kristoffersen b. 25.9.66 in Namsos. Cand. Scient. from Dept. of Informatics, University of Oslo in1993, Researcher at Norsk Regnesentral from 1993-1994, PhD student at Lancaster University 1994-

Jon O'Brien b. 13.11.70 in Cambridge. BA (Lancaster) Human Communication, Class I, PhD student 1993 - , Research Assistant, DTI/EPSRC VirtuOsi Project Apr '94 - Oct '95, responsible for ethnographic study of technology centre in manufacturing industry.

Mark Rouncefield b. 10.6.52 in Bristol. BA(Exeter), MA(Durham), MA (Lancaster) - Research Assistant DTI/EPSRC SYCOMT Project Oct '93 - , undertaking ethnographic studies of a financial institution. 